\title{
EXPERIMENTAL DEMONSTRATION OF HIGH POWER MILLIMETER WAVE GYRO-AMPLIFIERS*
}

\author{
M. Blank, J. Calame, B. Danly" ${ }^{\prime}$ B. Levush, J. Choi ${ }^{+}$, NRL, Washington DC \\ M. Garven, University of Maryland, College Park, MD \\ K. Nguyen, KN Research, Silver Spring, MD, D. Pershing, MRC, Newington, VA
}

\begin{abstract}
The Naval Research Laboratory is currently investigating gyro-amplifiers as high power, broadband sources for millimeter wave radars. A three-cavity Kaband gyroklystron achieved $225 \mathrm{~kW}$ peak output power with $0.82 \%$ bandwidth. At W-band, several multi-cavity gyro-amplifiers have been experimentally demonstrated. A four-cavity gyroklystron amplifier has achieved $84 \mathrm{~kW}$ peak output power at $34 \%$ efficiency with $370 \mathrm{MHz}$ bandwidth. A five-cavity gyroklystron demonstrated 72 $\mathrm{kW}$ peak output power with $410 \mathrm{MHz}$ bandwidth and 50 $\mathrm{dB}$ saturated gain. For applications requiring greater bandwidth, gyrotwystron amplifiers are also under study. A four section W-band gyrotwystron demonstrated $50 \mathrm{~kW}$ peak output power at $925 \mathrm{MHz}$ bandwidth.
\end{abstract}

\section{KA-BAND GYROKLYSTRON EXPERIMENTS}

In the three-cavity Ka-band gyroklystron amplifier experiment an electron beam of up to $12 \mathrm{~A}$ is produced from a thermionic, double anode magnetron injection gun by applying voltages of $65-75 \mathrm{kV}$. The magnetic field at the cathode can be varied with the gun coils to control the beam velocity ratio, $\alpha\left(\mathrm{v}_{\perp} / \mathrm{v}_{\mathrm{z}}\right)$. The beam is adiabatically compressed as it enters the region of high magnetic field (approx. $13 \mathrm{kG}$ ) generated by the 14 coil superconducting magnet. The three cavities of the gyroklystron circuit are positioned in the region of constant magnetic field. Each cavity operates in the $\mathrm{TE}_{011}$ cylindrical waveguide mode. Drive power is directed into a passive $\mathrm{TE}_{411}$ coaxial resonator which surrounds the $\mathrm{TE}_{011}$ input cavity. Power is coupled to the circular-electric mode inside the inner cavity by four axial slots placed every 90 degrees in azimuth. The measured cold resonant frequency of the input cavity is $34.89 \mathrm{GHz}$ and the loaded $\mathrm{Q}_{\mathrm{L}}$ is 188 (primarily diffractive due to the coupling slots). The intermediate (buncher) cavity employs an annular ring of lossy ceramic against the upstream endwall to provide the desired cold-test $\mathrm{Q}_{\mathrm{L}}$ of 194 and a resonant frequency of $34.62 \mathrm{GHz}$. The downstream end of the output cavity employs an outward radial step and a nonlinear uptaper to achieve a cold-test $\mathrm{Q}_{\mathrm{L}}$ of 175 and a resonant frequency of $34.83 \mathrm{GHz}$. The frequency upshift due to the presence of the electron beam is approximately $70 \mathrm{MHz}$. The drift tubes between cavities are loaded with lossy ceramic rings to suppress instabilities. A $3.81 \mathrm{~cm}$, half-wavelength thick $\mathrm{BeO}$ disk positioned immediately after the pumping manifold functions as the output window. The experiment employed two different diagnostic systems for measuring output power. The main diagnostic was an anechoic chamber joined to the output waveguide which had an absolute accuracy of $8 \%$ and a relative accuracy of $0.25 \%$. A high-average power calorimeter with 5\% absolute accuracy was also used to confirm the higher power measurements.

Systematic studies were performed over a wide range of operating voltages, currents, magnetic fields, and drive frequencies. A peak power of $225 \mathrm{~kW}$ at $34.90 \mathrm{GHz}$, with a $-3 \mathrm{~dB}$ bandwidth of $0.82 \%$, a saturated gain of $30 \mathrm{~dB}$, and an efficiency of $31 \%$ was obtained. These values were measured with a beam voltage of $70.2 \mathrm{kV}$, a current of 10 $\mathrm{A}$, a magnetic field of $13.1 \mathrm{kG}$ and a pulse width of $2 \mu \mathrm{s}$. The beam velocity ratio $\alpha$ was determined to be $1.27 \pm$ 0.05 using a capacitive probe placed just upstream of the input cavity. Additional enhancements in bandwidth were achieved with magnetic field adjustments and changes in beam voltage and current, at the expense of output power. For example, raising the voltage to $73.10 \mathrm{kV}$ and the nominal magnetic field to $13.40 \mathrm{kG}$ produced a $-3 \mathrm{~dB}$ bandwidth of $0.94 \%$ but with a lower peak output power of $200 \mathrm{~kW}$ (shown in Fig. 1). The beam current was 10 A, and the efficiency was $27.5 \%$ for this case. Detailed studies of how the bandwidth varies with operating parameters, along with comparisons to theory is summarised in [1]. In general, the measured bandwidth of the three-cavity device is 2.0-2.7 times as large as that obtained from the previous two-cavity gyroklystron experiment [2].

\section{W-BAND GYRO-AMPLIFIER EXPERIMENTS}

Several TE011 mode W-band gyro-amplifiers amplifiers operating near the fundamental cyclotron frequency have been built and tested. Each circuit consists of four or five interaction sections separated by drift sections cutoff to the operating mode. For each circuit, a coaxial drive

\footnotetext{
*Work supported by ONR.

"Email: danly@nrl.navy.mil

+ Current Address: Kwangwoon University, Seoul, South Korea.
} 
cavity, similar to that described above for the Ka-band experiment, was used. The input cavity parameters were determined through theoretical modeling with HFSS, a finite element code that computes field distributions and S-parameters for passive 3D structures.

As in the case of the Ka-band buncher cavity, the desired Q values (100-200) of the intermediate cavities are achieved by ohmically loading the cavities with rings of lossy ceramic placed at one end of each cavity. In the output sections, where no ceramic loading is used, power is diffactively coupled through a 5 degree linear uptaper to the collector radius. For each circuit, the parameters of the intermediate cavities and the output cavities/sections were determined through cold test measurements. A 2 $\mathrm{kW}$ peak power, mechanically tunable Extended Interaction Oscillator was used to supply the drive power. The tests were typically performed with $2 \mu$ sec pulses at $250 \mathrm{~Hz}$ for $0.05 \%$ duty. The measured results for five recently demonstrated W-band gyro-amplifier circuits are shown in Table 1.

TABLE 1. Measured performance of NRL W-band gyroamplifiers.

\begin{tabular}{|l|l|l|l|l|}
\hline Circuit & $\begin{array}{l}\text { Peak } \\
\text { Power } \\
(\mathrm{kW})\end{array}$ & $\begin{array}{l}\text { Efficiency } \\
(\%)\end{array}$ & $\begin{array}{l}\text { BW } \\
(\mathrm{MHz})\end{array}$ & $\begin{array}{l}\text { Gain } \\
(\mathrm{dB})\end{array}$ \\
\hline WGKL1 & 67 & 28 & 460 & 29 \\
\hline WGKL2 & 60 & 25 & 640 & 27 \\
\hline WGKL3 & 84 & 34 & 370 & 42 \\
\hline WGKL4 & 72 & 27 & 410 & 50 \\
\hline WGTWY & 50 & 18 & 925 & 30 \\
\hline
\end{tabular}

Results from the WGKL1 circuit [3], which was used to benchmark the design tools, and WGKL2 [4] have been previously reported. The WGKL 3 circuit was designed to demonstrate high peak output power and efficiency at moderate bandwidths. The efficiency and peak output power as functions of drive frequency for a $56 \mathrm{kV}, 4.4 \mathrm{~A}$ electron beam are shown in Fig. 2. In the figure, experimental data points are indicated by the filled circles and the predictions of theory are shown by the solid line. The measured results are in good agreement with theoretical predictions. Also shown on Fig. 2 are the resonant frequencies and Q's for each cavity, determined by modeling (cavity 1) and cold test (cavities 2-4). The high efficiency is achieved through the combination of the high Q output cavity and the minimized stagger tuning of the intermediate cavities about the resonant frequency of the output cavity.

The five cavity WGKL4 circuit was designed to demonstrate large gain, as well as high power and efficiency. A peak saturated output power of $72 \mathrm{~kW}$ was produced for a $54 \mathrm{kV}, 5 \mathrm{~A}$ electron beam with $1 \mathrm{~W}$ drive power, corresponding to $50 \mathrm{~dB}$ saturated gain. In the experiment, the drive power was measured at the output of the EIO driver and the losses in the drive line and input cavity were not taken into account.

In the four section WGTWY1 circuit, the output cavity was replaced by a travelling wave section to maximise the bandwidth of the device. Figure 3 shows the measured and theoretically predicted peak output power and efficiency versus drive frequency for a $57 \mathrm{kV}, 5 \mathrm{~A}$ electron beam. As shown in Fig.2, the measured FWHM bandwidth was $925 \mathrm{MHz}$ and the peak output power was $50 \mathrm{~kW}$, corresponding to a power-bandwidth product of $46.25 \mathrm{~kW}-\mathrm{GHz}$. This power-bandwidth product represents a significant increase over the powerbandwidth product of the gyroklystron amplifiers (see Table 1). The measured data and predictions of non-linear theory are in good agreement. The cavity and output section parameters are also indicated on the plot. The traveling wave output section has a measured Q of 70, which is $15 \%$ below the minimum diffractive $\mathrm{Q}$.

\section{SUMMARY}

Several multi-cavity Ka-band and W-band gyro-amplifiers have been experimentally demonstrated at the Naval Research Laboratory. Each circuit was designed to optimize certain aspects of performance such as output power, bandwidth, or gain. A three-cavity, Ka-band gyroklystron amplifier has demonstrated a peak output power of $225 \mathrm{~kW}$ at $34.90 \mathrm{GHz}$, with a $-3 \mathrm{~dB}$ bandwidth of $0.82 \%, 30 \mathrm{~dB}$ saturated gain and $31 \%$ efficiency. A four-cavity gyroklystron amplifier has achieved $84 \mathrm{~kW}$ peak output power at $34 \%$ efficiency with $370 \mathrm{MHz}$ bandwidth. A five-cavity gyroklystron demonstrated 72 $\mathrm{kW}$ peak output power with $400 \mathrm{MHz}$ bandwidth and 48 $\mathrm{dB}$ saturated gain. A four section W-band gyrotwystron demonstrated $50 \mathrm{~kW}$ peak output power at $925 \mathrm{MHz}$ bandwidth. The measured results were found to be in good agreement with theoretical performance predictions.

\section{REFERENCES}

[1] J.P. Calame et al. Physics Plasmas, 6, 285, 1998

[2] J. J. Choi et al. IEEE Trans. Plasma Sci.26, 416, 1998.

[3] M. Blank et al., Phys. Rev. Lett.. 79, 4485, 1997.

[4] M. Blank et al.,IEEE Trans. Plasma .Sci.,26, 409,1998 
Proceedings of the 1999 Particle Accelerator Conference, New York, 1999

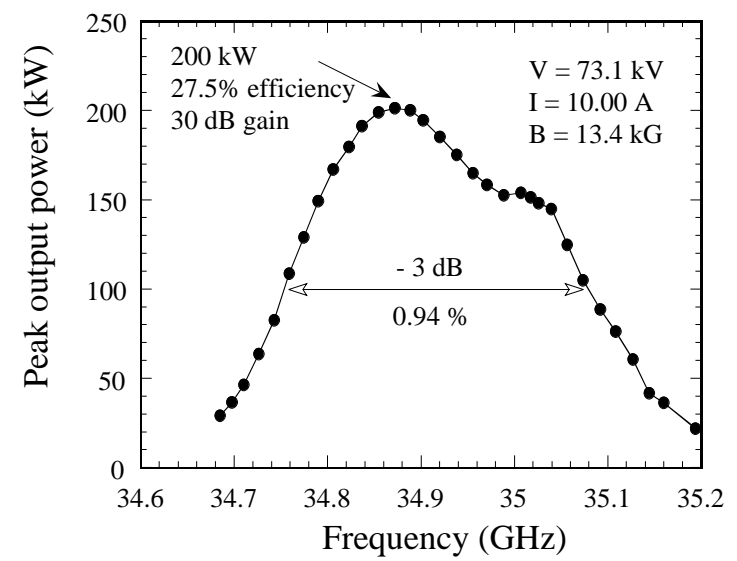

Fig. 1 Experimental frequency response of 3 cavity Ka-band circuit at $13.4 \mathrm{kG}$

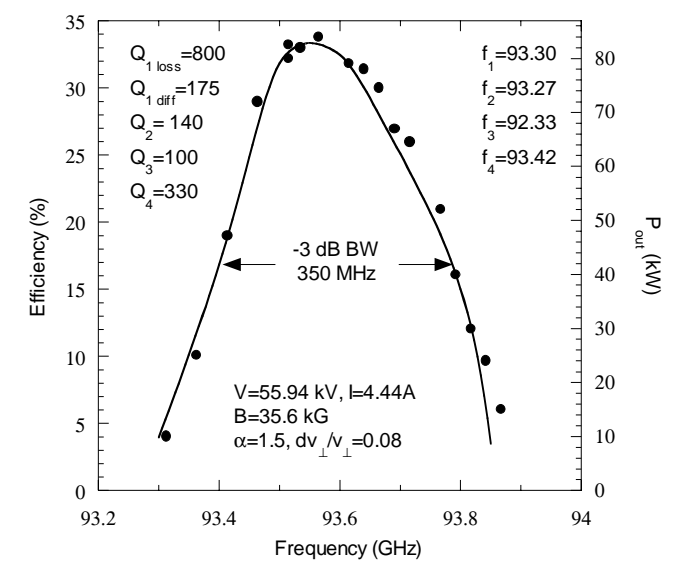

Fig 2. Measured (filled circles) and theoretical (solid line) peak output power and efficiency versus drive frequency for the WGKL3 circuit

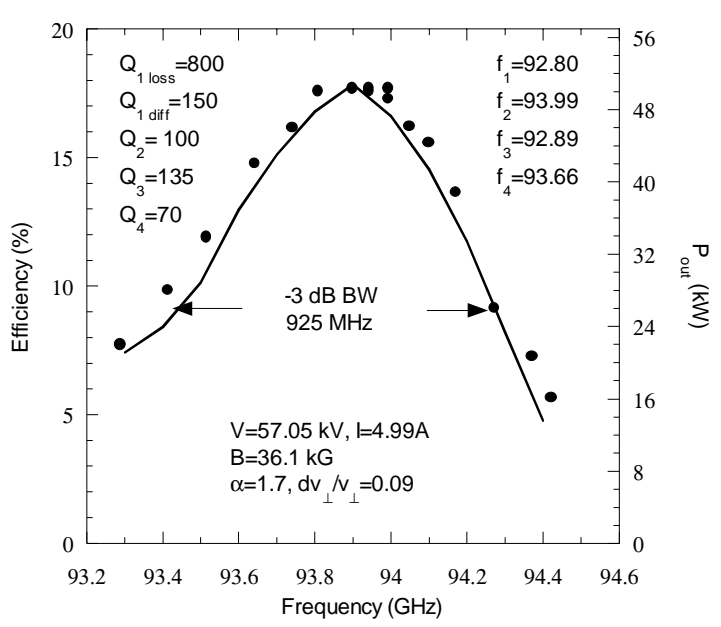

Fig 3. Measured (filled circles) and theoretical (solid line) peak output power and efficiency versus drive frequency for the WGTWY circuit 